A C T A C H E I C A S C A N D I A I C A 22 (1968) 597-606

\title{
Fractionation and Characterization of Arylamidases in Regenerating Wound Tissue
}

\author{
PIRKKO-LIISA MÄKINEN and JYRKI RAEKALLIO
}

Department of Forensic Medicine, University of Turku, Turku 3, Finland

\begin{abstract}
The formation and characteristics of enzymes hydrolysing particularly 2-naphthylamides of $\mathrm{L}$-valine and $\mathrm{L}$-methionine in the healing wound tissue of the rat were studied. The arylamidase activities were separated from one day old wounds into several enzyme fractions by CM and DEAE cellulose chromatography and by gel filtration on Sephadex G-200. The results showed that there is more arylamidase activity toward 2-naphthylamides of $\mathrm{L}$-valine and $\mathrm{L}$-methionine in the wound tissue than in the normal skin. The disc electrophoretic studies showed that new protein bands could be seen and that they coincided with the increased arylamidase activity. In general, the molecular weights of the one day old wound tissue arylamidases seemed to be lower than that in the normal skin enzymes as estimated by gel filtration. In the two days old wounds the arylamidases had larger molecular weights than the enzymes one day earlier. The effect of cysteine, dithiothreitol, reduced glutathione, EDTA, certain SHreagents, and heavy metal cations on the action of the arylamidases was studied. The results were compared with those of other investigations on arylamidases of animal tissues.
\end{abstract}

Tn the previous paper some suggestions concerning the increased activities 1 of aminopeptidase-like enzymes in the healing wounds of the rat were introduced..$^{1}$ It seemed possible that the formation of enzymes, differing from those of the normal skin or occurring there in such low quantities that they are difficult to discover, takes place in the regenerating tissue during the early phases of wound healing. This paper deals with the formation and characteristics of enzymes hydrolysing, for instance, 2-naphthylamides of L-valine and $L_{1}$-methonine in the wound tissue of the rat. The term arylamidase is used in this paper.

\section{MATERIALS AND METHODS}

Reagents. The 2-naphthylamides of amino acids and $N$-ethylmaleimide (NEM) were purchased from Mann Research Laboratories Inc. (New York, USA). Diethyl-p-nitrophenyl phosphate (E-600) was purchased from Fluka AG (Buchs, Switzerland), dithio- 
threitol and sodium $p$-chloromercuribenzoate (pCMB) from Calbiochem (Los Angeles, USA). All other reagents were obtained from E. Merck AG (Darmstadt, Germany).

Preparation of normal and wound tissue samples. Albino rats, from 4 to 9 months old and of both sexes, were used. The wounds were made and the material was prepared chiefly as is described in the previous paper. ${ }^{1}$ For the preparation of wound and normal tissue samples, sections were cut from the tissue in question in a cryostat in the follow ing way, based on histochemical observations on the pattern of enzyme activities in healing wounds. ${ }^{2}$ Firstly, a hundred sections of $16 \mu$ were cut for the preparation of the wound sample. Secondly, a further hundred sections were discarded, and a final hundred sections of $16 \mu$ were taken for the sample of the normal skin. Consequently, samples of both wound tissue and normal tissue were always obtained from the same flap of skin. The idea was to take samples of quite equal zones from the wound and from the normal skin for further preparation, which is described under "Disc electrophoresis". In this study one day old skin wounds were principally used since the arylamidase activity is highly increased at this phase of healing. ${ }^{1}$

Chemical determinations. The determination of enzyme activities and of protein concentrations was performed as described earlier. ${ }^{1}$ When reducing compounds (cysteine, reduced glutathione, and dithiothreitol) were added to the reaction mixtures, the amount of liberated 2-naphthylamide was determined by the Bratton-Marshall reaction. ${ }^{3}$ When studying the effect of modifying compounds, the water normally present in the reaction mixtures was replaced by aqueous solutions of the modifiers. The divalent cations were used as chloride salts. The reaction mixtures were preincubated for $\mathbf{3 0} \mathrm{min}$ in the absence of the substrate. After that time the substrate was added and the mixtures were incubated for 60 minutes.

Column chromatography. In the preparation of the ion exchange columns and in conducting the fractionation the instructions of Peterson and Sober ${ }^{4}$ have been followed with the exceptions mentioned in the earlier paper. ${ }^{1}$ The gel filtration was conducted on Sephadex $\mathrm{G}-200^{\circ}$ columns following the instructions of the manufacturer of the gel (Pharmacia, Uppsala, Sweden).

Disc electrophoresis. Disc electrophoresis was conducted with a Canalco Model 6 electrophoresis apparatus following the method of Ornstein and Davis. The samples were obtained by pooling proper enzymatically active fractions from CM cellulose fractionation, precipitating the proteins with ammonium sulphate (90\% saturated), dissolving the precipitate in $1 \mathrm{ml}$ of $0.01 \mathrm{M}$ tris $-\mathrm{HCl}$ buffer, $\mathrm{pH} 7.15$, passing the solution through a Sephadex G-25 column $(10 \times 180 \mathrm{~mm})$ with the aid of $0.01 \mathrm{M}$ tris-HCl buffer of pH 7.15 at $22^{\circ} \mathrm{C}$, and freeze-drying the resulting solution. In the ammonium sulphate precipitation the mixture was allowed to stand at $4^{\circ} \mathrm{C}$ for $30 \mathrm{~min}$ and then it was centrifuged for $10 \mathrm{~min}$ at $23500 \mathrm{~g}$. Direct freeze-drying of the pooled fraction was not convenient because of the high amounts of sodium chloride present in the enzyme solutions. Therefore the precipitation by ammonium sulphate and desalting with Sephadex G-25 was necessary. After freeze-drying the dry material was dissolved in $0.1 \mathrm{ml}$ of cold water and from 5 to $20 \mu \mathrm{l}$ of the resulting solution was applied on the polyacrylamide columns. The exact volumes of the samples are given in Results.

\section{RESULTS}

Fractionation of enzymes. First we tried to elucidate the number and homogeneity of the enzymes hydrolysing L-valyl- and L-methionyl-2-naphthylamide in the wound tissue. These substrates were chosen because their rates of hydrolysis are markedly higher in the wound tissue than in the normal skin. ${ }^{1}$ The enzyme samples were first fractionated on a CM cellulose column and the material of the resultant peaks on a DEAE column. The chromatograms shown in Fig. 1 were obtained. The chromatograms show that several enzymes hydrolysing both substrates occur in the wound tissue. The enzyme peaks obtained in these fractionations were not homogeneous and obviously more than one single enzyme is involved, at least in some of the peaks. 
Fig. 1. Fractionation of one day old wound tissue preparation by CM cellulose (A) column followed by fractionation by DEAE cellulose (B and $\mathrm{C}$ ).

CM cellulose fractionation. Column: $\mathrm{CM}$ cellulose, $15 \times 850 \mathrm{~mm}$ (Schleicher \& Schüll, 140-200 mesh); Elution: 0.01 M tris-HCl, $\mathrm{pH}$ 7.15; Salt gradient: linear sodium chloride gradient from 0 to $1.5 \mathrm{M}$ (mixing volume $100+100 \mathrm{ml}$ ); Temperature: $+4^{\circ} \mathrm{C}$; Hydrostatic pressure: about $100 \mathrm{~cm} \mathrm{H}_{2} \mathrm{O}$; Flow rate: about $6 \mathrm{ml} / \mathrm{h}$ during elution; Fraction volume: $2 \mathrm{ml}$.

$D E A E$ fractionation. Column: DEAE cellulose, $10 \times 200 \mathrm{~mm}$ (Schleicher \& Schüll, 140-200 mesh); Elution: 0.01 M tris- $\mathrm{HCl}$, $\mathrm{pH}$ 7.15; Salt gradient: linear sodium chloride gradient from 0 to $1.5 \mathrm{M}$ (mixing volume $70+70 \mathrm{ml})$; Temperature: $+4^{\circ} \mathrm{C}$; Hydrostatic pressure: about $100 \mathrm{~cm} \mathrm{H}_{2} \mathrm{O}$; Flow rate: about $6 \mathrm{ml} / \mathrm{h}$ during elution; Fraction volume: $0.75 \mathrm{ml}$.

For DEAE fractionations marked with B and $C$ the enzyme preparations were obtained by pooling the active fractions from CM cellulose fractionation as indicated by the dotted line. Only for the second DEAE fractionation (C) was the enzyme preparation first transferred into the ionic strength of the starting buffer by passing the saltrich enzyme solution through a Sephadex

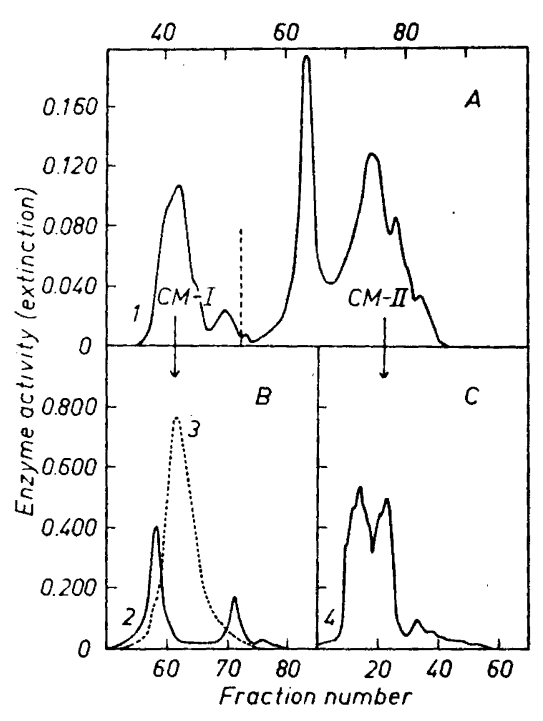

G-25 column. 1 = L-Valyl-2-naphthylamide, CM cellulose fractionation. $\mathbf{2}=\mathrm{I}$ Methionyl-2-naphthylamide, DEAE cellulose fractionation. 3 = L-Arginyl-2-naphthylamide, DEAE cellulose fractionation. $4=$ L-Valyl-2-naphthylamide, DEAE cellulose fractionation.

Figs. $2 \mathrm{a}$ and $2 \mathrm{~b}$ confirm the results obtained earlier, ${ }^{1}$ that the one day old wound tissue indeed contains more enzyme activity toward L-valyl- and L-methionyl-2-naphthylamide than the normal tissue. The molecular weights of the newly formed enzymes do not differ very much from each other, because only one quite new (as compared with the normal skin) main enzyme peak (Sephadex-II) is obtained when fractionating the enzyme samples on a Sephadex G-200 column. In contrast, the molecular weights of the wound tissue enzymes seem to be lower as compared to the majority of the normal skin enzymes (Sephadex-I in Fig. 2 a). On the other hand, in the case of two days old wound tissue, fractionated with Sephadex G-200 (Fig. 2 c), one can see that the majority of these enzymes correspond to molecules of higher molecular weight than those in the one day old wound tissue.

Effect of modifiers. The effect of some modifiers was tested on the pooled arylamidase fractions from CM cellulose and Sephadex G-200 fractionations. In these experiments the main attention was paid to the revealing of possible differences between arylamidases of the normal skin and those of the wound tissue. The results are given in Tables 1 and 2 . Because of the insufficient purity of the enzyme preparations obtained, no exact quantitative expressions are used, but only a percentage of inhibition or activation. The normal skin preparation was obtained from Sephadex G-200 fractionations of the normal skin homogenate of the rat (marked as Sephadex-I in Fig. 2 a). The most

Acta Chem. Scand. 22 (1968) No. 2 


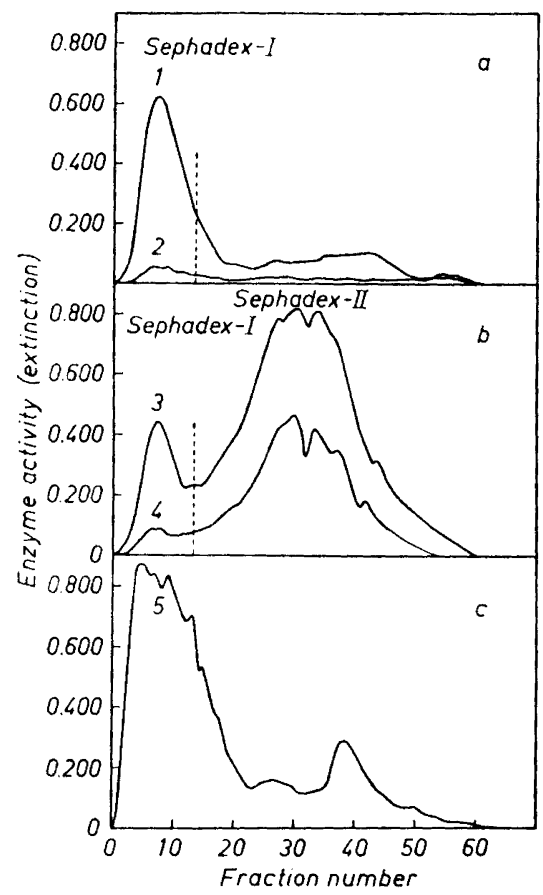

Fig. 2. $a$ : Gel filtration of rat normal skin arylamidases. Column: Sephadex G-200, $15 \times 900 \mathrm{~mm}$; Elution: $0.05 \mathrm{M}$ tris- $\mathrm{HCl}$, pH 7.15; Temperature: $+4^{\circ} \mathrm{C}$; Hydrostatic pressure: $15 \mathrm{~cm} \mathrm{H}_{2} \mathrm{O}$; Flow rate: $5 \mathrm{ml} / \mathrm{h}$; Fraction volume: 15 . ml; Void volume: 59 $\mathrm{ml}$ (determined with Blue Dextran). $1=\mathrm{L}$ Methionyl-2-naphthylamide. $2=$ L-Valyl2-naphthylamide. $b$ : Gel filtration of one day old wound tissue preparation. Fractionation was performed identically with that in Fig. 2 a. $3=$ L-Methionyl-2-naphthylamide. $4=$ L-Valyl-2-naphthylamide. c: Gel filtration of two days old wound tissue preparation. Fractionation was performed identically with that in Fig. 2 a. $5=$ L-Methionyl-2-naphthylamide.

Table 1. Modifier characteristics of arylamidase fractions (Sephadex G-200 fractionation in Fig. $2 a$ and b) from one day old wound tissue and from normal skin. The substrate was I-methionyl-2-naphthylamide.

\begin{tabular}{|c|c|c|c|c|c|c|}
\hline \multirow{3}{*}{$\begin{array}{l}\text { Sample } \\
\text { Name of fraction } \\
\begin{array}{l}\text { Modifier } \\
\text { concentration (M) }\end{array}\end{array}$} & \multirow{2}{*}{\multicolumn{2}{|c|}{$\frac{\text { Normal skin }}{\text { Sephadex.I }}$}} & \multicolumn{4}{|c|}{ Wound tissue } \\
\hline & & & \multicolumn{2}{|c|}{ Sephadex-I } & \multicolumn{2}{|c|}{ Sephadex-II } \\
\hline & $10^{-5}$ & $10^{-3}$ & $10^{-5}$ & $10^{-3}$ & $10^{-5}$ & $10^{-3}$ \\
\hline Water & 100 & 100 & 100 & 100 & 100 & 100 \\
\hline EDTA & 43 & 26 & 68 & 69 & 113 & 114 \\
\hline $\mathrm{KCN}$ & 111 & 97 & 100 & 100 & 100 & 111 \\
\hline $\mathrm{CaCl}_{2}$ & 109 & 100 & 100 & 100 & 96 & 71 \\
\hline $\mathrm{MgCl}_{2}^{2}$ & 100 & 100 & 100 & 100 & 100 & 100 \\
\hline $\mathrm{CoCl}_{2}$ & 124 & 134 & 124 & 100 & 84 & 17 \\
\hline $\mathrm{MnCl}_{2}$ & 100 & 74 & 107 & 96 & 94 & 79 \\
\hline E-600 & 100 & 95 & 100 & 100 & 97 & 74 \\
\hline NEM & 100 & 92 & 109 & 89 & 98 & 53 \\
\hline pCMB & 100 & & 92 & & 10 & \\
\hline L-Cysteine & 100 & 88 & 105 & 115 & 101 & 148 \\
\hline Reduced glutathione & 100 & 79 & 100 & 107 & 111 & 133 \\
\hline
\end{tabular}

Acta Chem. Scand. 22 (1968) No. 2 
Table 2. Modifier characteristics of arylamidase fractions (CM cellulose fractionation in Fig. 1 A.) from one day old wound tissue. The substrate was L-valyl-2-naphthylamide.

\begin{tabular}{|l|r|r|r|r|}
\hline Samples & \multicolumn{4}{|c|}{ Wound tissue } \\
\cline { 2 - 5 } Name of the fraction & \multicolumn{2}{|c|}{ CM-I } & \multicolumn{3}{c|}{ CM-II } \\
\hline Modifier concentration (M) & $10^{-5}$ & $10^{-3}$ & $10^{-5}$ & $10^{-3}$ \\
\hline & 100 & 100 & 100 & 100 \\
Water & 33 & 26 & 167 & 144 \\
EDTA & 100 & 100 & 126 & 227 \\
KCN & 100 & 100 & 100 & 57 \\
$\mathrm{CaCl}_{2}$ & 100 & 100 & 100 & 100 \\
$\mathrm{MgCl}_{2}$ & 100 & 78 & 87 & 15 \\
$\mathrm{CoCl}_{2}$ & 100 & 66 & 80 & 65 \\
$\mathrm{MnCl}_{2}$ & 100 & 92 & 100 & 45 \\
E-600 & 96 & 76 & 75 & 38 \\
NCM & 100 & 117 & 170 & 291 \\
LCMB & 100 & 116 & 176 & 202 \\
Reduced glutathione & 100 & 100 & 125 & \\
\hline
\end{tabular}

important observations are as follows. EDTA, $10^{-5}-10^{-3} \mathrm{M}$, produced about $60-70 \%$ inhibition. Cyanide ions had hardly any effect, whereas $\mathrm{Co}$ (II) ion activated the enzymes of this fraction. Mild inhibition or no effect was caused by cysteine and reduced glutathione. pCMB did not inhibit the enzymes involved.

When studying the modifier characteristics of the wound tissue the enzyme preparations were obtained from Sephadex G-200 fractionations (marked as Sephadex-I and Sephadex-II in Fig. 2 b). The effect of the above mentioned modifiers on the enzymes of the Sephadex-I pool was nearly the same as on those of the normal skin. It seems possible that this enzyme pool in the wound tissue fractionation consists, at least partly, of those arylamidases most active in the normal skin. This is also suggested by the similarities of the elution patterns of the first enzyme peaks in Figs. 2 a and $2 \mathrm{~b}$. The enzyme preparation Sephadex-II (Fig. 2 b) consists of the essential wound tissue arylamidases. These enzymes are activated by EDTA and cyanide ions differing in this respect from the normal skin enzymes. Further differences are found when studying the effect of other modifiers. Co(II) ions had no activating effect, but they strongly inhibited the wound enzymes at $10^{-3} \mathrm{M}$. Cysteine, dithiothreitol, and reduced glutathione activated the enzymes in question. These enzymes were also inhibited by $\mathrm{pCMB}$ and NEM. The inhibitory effect of pCMB and NEM could not be noticed in the presence of $10^{-4} \mathrm{M}$ cysteine.

The modifier characteristics of the arylamidases obtained by CM cellulose fractionations resembled the characteristics obtained with enzyme fractions from Sephadex G-200 filtration. However, one could see still stronger activation by cysteine and reduced glutathione in the enzyme fractions pooled from the CM cellulose fractionation. This could be due to different combination of the enzymes in the two main peaks obtained (CM-I and CM-II in Fig. 3) as compared to those in the Sephadex G-200 fractionation.

Acta Chem. Scand. 22 (1968) No. 2 


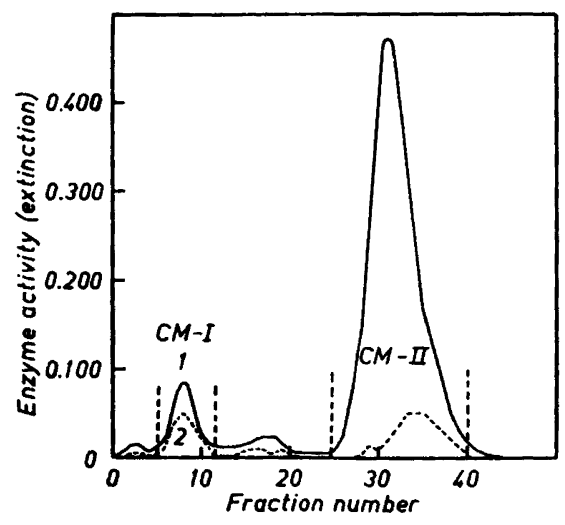

Fig. 3. Fractionation of the one day old wound tissue and normal skin preparations by $\mathrm{CM}$ cellulose. Column: CM cellulose, $10 \times 200 \mathrm{~mm}$ (Schleicher \& Schüll, 140200 mesh); Elution: $0.01 \mathrm{M}$ tris- $\mathrm{HCl}+10^{-3}$ M cysteine, $\mathrm{pH}$ 7.15; Salt gradient: linear sodium chloride gradient from 0 to $1.5 \mathrm{M}$ (mixing vloume $50+50 \mathrm{ml}$ ); Temperature: $+4^{\circ} \mathrm{C}$; Hydrostatic pressure: about $100 \mathrm{~cm}$ $\mathrm{H}_{2} \mathrm{O}$ during elution; Flow rate: about 6 $\mathrm{ml} / \mathrm{h}$; Fraction volume: $1.3 \mathrm{ml}$; Sample: cryostat-cut sections from 10 wounds were homogenized with Ultra-Turrax homogenizer in $4 \mathrm{ml}$ of water, centrifuged for 10 min at $23500 \mathrm{~g}$. The supernatant was applied on the column. The chromatogram has not the same form as that in Fig. 1A due to the fact that the mixing volumes were not the same. $1=$ wound tissue $(-) \cdot 2=$ normal skin $(---)$.

Disc electrophoresis. As mentioned under "Preparation of normal and wound tissue samples" equal samples of material from the wound tissue and from the normal skin of the same rat were taken in order to elucidate whether protein synthesis, instead of some kind of enzyme activation, had occurred during the wound healing. The homogenization, $\mathrm{CM}$ cellulose fractionation, ammonium sulphate precipitation, desalting procedure, freeze-drying, and disc electrophoresis were conducted identically with both samples. The results are given in Figs. 3-8. In Fig. 3 the elution patterns of the CM cellulose fractionation are presented. The fractions marked CM-I and CM-II were used for further treatment. Fig. 4 shows the chromatograms of the supernatant of the homogenate of the wound and the normal tissue. Figs. 5-8 show the chromatograms and the arylamidase activities from the freeze-dried CM cellulose fractions of the wound tissue and of the normal skin. These figures show the presence of certain new or stronger protein bands in the gel slabs, and the peaks corresponding to the arylamidase activity coincide with these bands. The activity of the enzymes in the CM-I pool was determined by L-methionyl-2naphthylamide, because this substrate is hydrolysed more rapidly than $L_{-}$valyl-2-naphthylamide, which, on the other hand, was a better substrate for the enzymes in the CM-II pool.

Substrate specificity. The enzyme preparations used for the substrate specificity studies were obtained from CM and DEAE cellulose fractionations

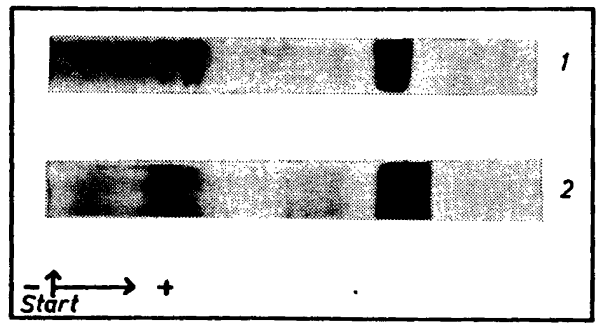

Fig. 4. Disc electrophoresis of freeze-dried supernatants $(5 \mu \mathrm{l})$ of normal and wound tissue (one day old) homogenates stained with Amido Black). $1=$ wound tissue. 2 = normal skin. 


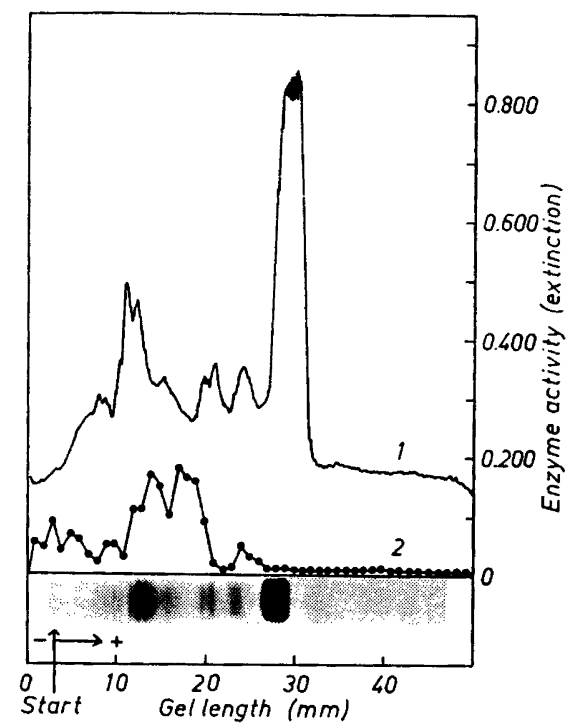

Fig. 5. Disc electrophoresis of a sample $(5 \mu 1)$ of the enzyme peak marked with CM-I in Fig. 3 (normal skin). The enzyme preparation was obtained by freeze-drying the pooled fraction, dissolving the remained material in $0.1 \mathrm{ml}$ of cold water.

1 = Densitometer tracing of the gel slab stained with Amido Black and scanned with the Chromoscan densitometer (Joyce \& LoebI, England) using the 3 O.D. filter.

2 = Arylamidase activity curve of $1 \mathrm{~mm}$ sections of the gel obtained with $\mathrm{L}$ methionyl-2-naphthylamide. The proteins in the sections were extracted for $3 \mathrm{~h}$ with $0.25 \mathrm{ml}$ of $0.01 \mathrm{M}$ tris $-\mathrm{HCl}$, $\mathrm{pH}$ 7.15. The enzyme activity of the extracts was determined by adding $0.15 \mathrm{ml}$ of $10^{-3} \mathrm{M}$ substrate solution to the mixture. Incubation was carried out for $13 \mathrm{~h}$ and the reactions were stopped by Fast Garnet GBC solution.

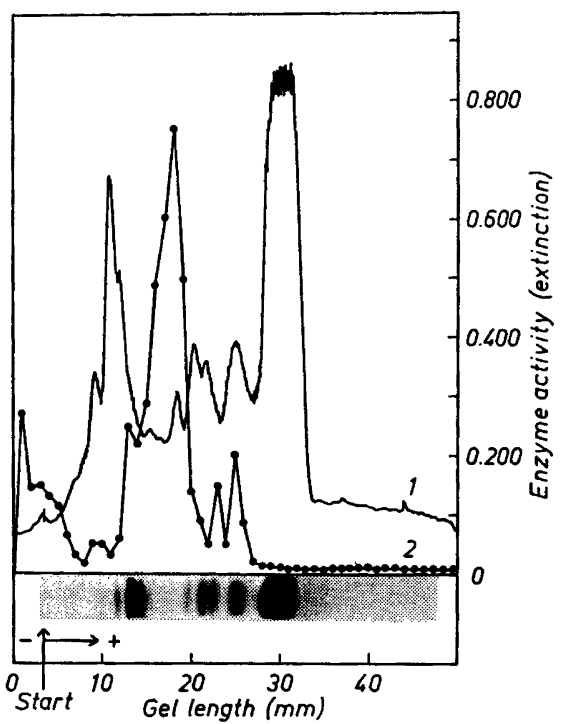

Fig. 6. The same as in Fig 5, but the enzyme preparation was obtained from wound tissue fractionation.

(Fig. 1) and by gel filtration on Sephadex G-200 (Fig. 2 b). The first arylamidase peak obtained through CM cellulose fractionation could be further separated into three different enzyme peaks by DEAE fractionation. The first and the third of these arylamidase fractions hydrolysed most rapidly the 2-naphthylamides of L-methionine, L-alanine, L-leucine, and L-phenylalanine. The second arylamidase hydrolysed most rapidly the 2-naphthylamides of the basic amino acids, L-arginine and L-lysine. In Sephadex G-200 fractionations the arylamidases hydrolysing the basic amino acids were eluted together with the so 


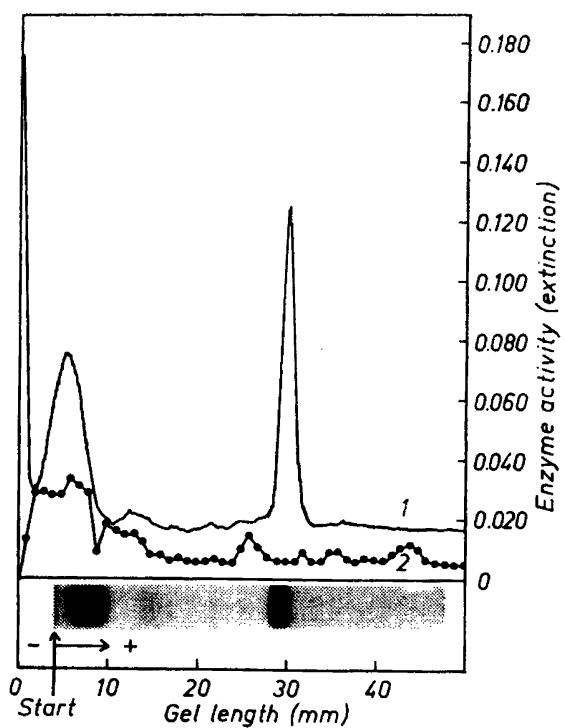

Fig. 7. Disc electrophoresis of a sample (20 $\mu 1)$ of the enzyme peak marked with CM-II in Fig. 3 (normal skin). The preparation was obtained by precipitating the proteins of the pooled fraction with ammonium sulphate, dissolving the precipitate in $1 \mathrm{ml}$ of $0.01 \mathrm{M}$ tris-HCl, passing it through a Sephadex G-25 column and freeze-drying the resulting solution. The remaining material was finally dissolved in $0.1 \mathrm{ml}$ of cold water. The other explanations are as in Fig. 5, but the substrate was $I_{1}$-valyl-2naphthylamide.

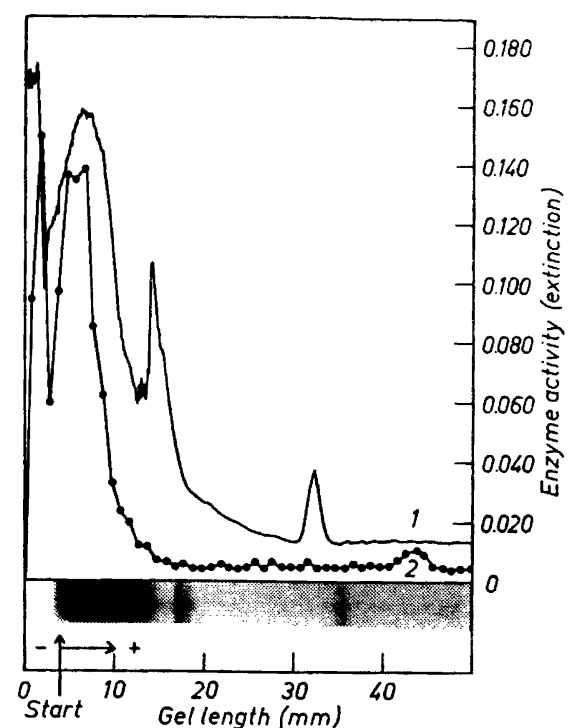

Fig. 8. The same as in Fig. 7, but the enzyme preparation was obtained from wound tissue.

called wound specific enzymes (Sephadex-II in Fig. 2 b). The arylamidase activity of the other peaks from CM cellulose fractionation was tested in the presence of $1.4 \times 10^{-3} \mathrm{M}$ dithiothreitol because of the lability of these enzymes. In the arylamidase fractions $60-70$ (Fig. $1 \mathrm{~A}$ ) the most rapidly hydrolysed substrates were the 2-naphthylamides of $L$-phenylalanine, $\mathrm{L}_{\mathrm{H}}$-lysine, $\mathrm{L}$-methio-

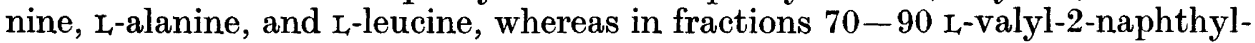
amide was hydrolysed most rapidly, the next best substrate being $L_{-}$-methionyl2-naphthylamide.

\section{DISCUSSION}

Fractionation of enzymes. In the Sephadex G-200 fractionations (Figs. 2 a, $b$, and c) performed in this study two distinct groups of arylamidases were separated from the wound tissue preparation. Both of these groups seem to consist of more than one single enzyme. As can be seen in Fig. 2 b, the molec- 
ular weights of the arylamidases, characteristic of the one day old wound tissue (Sephadex-II), do not differ very much from each other. These enzymes are, however, smaller molecules than those chiefly present in the normal skin (Fig. 2 a). These arylamidases of smaller molecular weight are either not very active or they do not occur in large amounts in the normal skin of the rat, but their quantity increases very clearly during wound healing. In the preparations from two days old wounds, fractionated also by Sephadex G-200, the majority of the revealed arylamidases have larger molecular weights (Fig. 2 c) than those in the preparations from one day old wounds. It seems that the smaller molecules are the first to appear in the wound tissue followed by larger ones. Consequently, one could suggest that the arylamidases in question are already active although the biosynthesis of the enzyme proteins is not yet completed, and that these numerous arylamidases of the wound tissue represent the same enzyme(s) in different degrees of formation. Another explanation could, be that, corresponding to the variable functional demands, there are two or possibly more groups of arylamidases having different molecular weights and a different function in the tissue.

The latter explanation is perhaps supported by the investigations of Mahadevan et $a l . .^{5}$ who have suggested that there are two different groups of arylamidases in rat liver and kidney, the lysosomal and microsomal arylamidases. These two groups of enzymes have different modifier characteristics and certain differences in stability.

The disc electrophoretic studies give a picture of the purity of the enzyme preparations obtained. Although the new protein bands, stainable by Amido Black, coincide well with the increased arylamidase activity on 2-naphthylamides of L-valine and L-methionine, the present results do not absolutely prove their correspondence, but do not disprove it either.

Effect of modifiers. When comparing the modifier characteristics of the enzymes demonstrated by Mahadevan et al. ${ }^{5}$ with those in the wound tissue of the present investigation certain similarities are to be seen. The arylamidases, whose amount had most increased in the wound tissue, were found to be activated by $\mathrm{SH}$-compounds like cysteine, reduced glutathione, and dithiothreitol, and they were inhibited by pCMB and NEM. It is possible that these enzyme molecules contain SH-groups that are easily oxidized during storage, this being also a reason for their high instability. All these characteristics resemble those demonstrated by Mahadevan et al. ${ }^{5}$ with rat liver and kidney lysosomal arylamidases. Further similarities were found in the inhibition of the arylamidases of all three sources, liver, kidney, and skin wound, by divalent metal cations, except magnesium, and in the activation of the enzymes by EDTA.

Those arylamidases, which are most active in normal skin of the rat, but whose amount is also obviously increased in the two days old wound tissue, are much more stable to storage. In addition, they are activated by $\mathrm{Co}$ (II) ions and inhibited by EDTA. Similar enzymes activated by $\mathrm{Co}(\mathrm{II})$ ions and inhibited by EDTA in rat liver and kidney have been described by Mahadevan et $a l .^{5}$ who called them microsomal arylamidases.

An arylamidase called LAP II which is activated by $\mathrm{Co}(\mathrm{II})$ ions and inhibited by EDTA has also been demonstrated in human skin by Decker 
et al. ${ }^{6}$ This enzyme can be demonstrated by histochemical methods employing L-leucyl-2-naphthylamide as substrate. It is possible that this enzyme is the same or very similar in nature to that demonstrated by Raekallio ${ }^{7}$ in the wound tissue. Because the histochemical demonstration of the increased enzyme activity in the wound tissue was not possible using, e.g. L-valyl-2naphthylamide, whose rate of hydrolysis is much more rapid by the wound tissue arylamidases than by the normal skin enzymes, it seems likely that only a fraction of the wound tissue arylamidase activity can be demonstrated histochemically. Consequently, it seems that there are indeed different kinds of arylamidases in the wound tissue.

Substrate specificity. As to the substrate specificity the arylamidases of the wound tissue do not seem to be strictly specific for a particular amino acid 2-naphthylamide. For instance, L-methionyl-2-naphthylamide seems to be the best substrate for more than one arylamidase of the wound tissue. As was shown earlier, ${ }^{1}$ the highest increase in enzyme activity in the wound tissue, as compared to the normal skin, could be demonstrated by L-valyl-2naphthylamide, whose rate of hydrolysis is very low by the normal skin enzymes. As a rule the rates of hydrolysis of the 2-naphthylamides of those amino acids having a branched chain at the $\beta$-carbon atom, are low as compared to the other amino acid 2-naphthylamides. This has been shown by Behal et al..$^{8,9}$ with the arylamidases of pancreas, intestine, liver, and plasma. In this connection it is interesting to observe that in the wound tissue there are enzymes catalysing rapidly the hydrolysis of the 2-naphthylamides of both $\mathrm{L}_{\text {-valine }}$ and $\mathrm{L}_{\text {-isoleucine. }}$

\section{REFERENCES}

1. Mäkinen, P.-L. and Raekallio, J. Acta Chem. Scand. 21 (1967) 761.

2. Raekallio, J. and Mäkinen, P.-L. Nature 213 (1967) 1037.

3. Goldbarg, J. A. and Rutenburg, A. M. Cancer 11 (1958) 283.

4. Peterson, E. A. and Sober, H. In Colowick, S. P. and Kaplan, N. O. Methods in Enzymology, Academic, New York 1962, Vol. V.

5. Mahadevan, S. and Tappel, A. L. J. Biol. Chem. 242 (1967) 2369.

6. Decker, R. H. and Dicken, C. H. J. Invest. Dermatol. 48 (1967) 128.

7. Raekallio, J. Nature 188 (1960) 234.

8. Behal, F.J., Asserson, B., Dawson, F. and Hardman, J. Arch. Biochem. Biophys. 111 (1965) 335.

9. Behal, F. J., Klein, R. A. and Dawson, F. B. Arch. Biochem. Biophys. 115 (1966) 545.

Received September 25, 1967. 